\title{
Subendocardial infarction and thrombocytopenia
}

\author{
Z. FIREMAN \\ M.D. \\ I. YUST \\ M.D. \\ J. ZAHAVI \\ Y. KAHN \\ M.D. \\ M.D. \\ L. A. Abramov \\ M.D.*

\begin{abstract}
*Department of Internal Medicine B, and the Institute of Hematology, Municipal Governmental
\end{abstract} \\ Medical Center, Ichilov Hospital, Tel-Aviv; The Sackler Medical School, University of Tel-Aviv, Israel
}

\begin{abstract}
Summary
Two female patients who suffered from drug-induced thrombocytopenic purpura and subendocardial myocardial infarction are presented. One of them died from cerebral haemorrhage and diffuse subendocardial punctate haemorrhages were found at post-mortem. The abnormal haemostasis which is associated with thrombocytopenia might induce diffuse damage of the myocardium and might impair heart performance. This finding may be more frequent than hitherto appreciated and calls for serial electrographic tracings in thrombocytopenic patients.
\end{abstract}

\section{Introduction}

Acute subendocardial ischaemia or infarction is reported as being rare in patients with moderate or severe thrombocytopenia (Cohen, 1974). In these cases, the initial white thrombus formation seems to be minimal or absent and the impaired haemostasis may result in purpura to the skin, mucous membranes and internal organs (Bowie and Owen, 1971) but rarely in the endocardium (Cohen 1974; Bowie and Owen, 1971).

Two female patients are reported who suffered from thrombocytopenic purpura and acute subendocardial infarction. Post-mortem examination of one patient revealed minimal atherosclerotic changes of the coronary blood vessels and diffuse subendocardial punctate haemorrhages.

\section{Case 1}

A 62-year-old white married woman had been in apparent good health until one week before her admission to hospital when she noticed the appearance of scattered punctate haemorrhages over both legs. In the preceding 4 months she had been treated intermittently with phenylbutazone $100-200 \mathrm{mg}$ daily, for arthralgia, and $\alpha$-methyldopa 0.5 daily, for mild hypertension.
On admission the blood pressure was $160 / 110$ $\mathrm{mmHg}$, and the pulse rate $84 / \mathrm{min}$. Heart, lung and abdomen were clinically normal. Diffuse purpura and a few ecchymoses were evenly distributed over both legs and right retina. Initial laboratory data showed a platelet count of $12.0 \times 10^{9} / 1$, and a haemoglobin level of $12 \cdot 6 \mathrm{~g} / \mathrm{dl}$. Blood glucose was $8.2 \mathrm{mmol} / \mathrm{l}$, WBC, serum urea, uric acid, cholesterol creatinine, lactic dehydrogenase (LDH), serum glutamic-oxaloacetic transaminase (SGOT), creatinine phosphokinase (CPK), bilirubin, serum protein electrophoresis and immunoelectrophoresis were all normal. Serological tests for anti-nuclear factor, lupus erythematosus preparations, anti-DNA and Coombs' direct and indirect tests were all negative. Bleeding time was prolonged to more than $12 \mathrm{~min}$ (normal, 4-7 min). The euglobulin lysis time, however, was slightly decreased (Table 1). Chest X-ray was normal. ECG showed normal sinus rhythm $84 / \mathrm{min}$, left axis deviation and incomplete right bundle branch block. Repeated bone marrow aspiration revealed complete absence of megakaryocytes and was compatible with drug-induced thrombocytopenia. Prednisone $60 \mathrm{mg}$ daily was given but without any effect on the platelet count which remained low $-20.0 \times 10^{\%} / 1$ during stay in hospital. The steroid dose was decreased to $30 \mathrm{mg}$ daily and the patient was discharged from the hospital in good condition. One month later she was readmitted because of severe retrosternal pain, lasting several hours. Physical examination of the heart, lung and abdomen was again normal. The ECG, however, showed fresh subendocardial infarction with inverted $T$ waves in $L_{3}$, avF and $V_{1}-V_{6}$. SGOT was slightly elevated to $45 \mathrm{u}$., while CPK and LDH were within normal limits. The clinical course was without complications. The ischaemic electrocardiographic changes gradually returned to normal and remained so during the following 6 months. 


\section{Case 2}

A 53-year-old woman was admitted to hospital because of disseminated purpura of the whole body which had appeared one week before. On examination, the heart, lungs and abdomen were clinically normal. ECG tracing showed sinus rhythm $68 / \mathrm{min}$, inverted $T$ waves in $L_{2} L_{3}$, avF, $V_{3}-V_{6}$ and isoelectric $T$ waves in $L_{1}$ and avL. Chest $\mathrm{X}$-ray was normal. Serum levels of SGOT, CPK and LDH were normal. Blood glucose, cholesterol, bilirubin, serum protein electrophoresis and immunoelectrophoresis, lupus erythematosus preparation, anti-DNA, anti-nuclear factor and Coombs' tests were within normal limits.

The platelet count was decreased to $20 \times 10^{9} / 1$ and bleeding time was prolonged to more than $12 \mathrm{~min}$. Other coagulation tests were all normal (Table 1).

'TABLE 1. Coagulation studies*

\begin{tabular}{lccc}
\hline \multicolumn{1}{c}{ Study } & $\begin{array}{l}\text { Normal } \\
\text { range }\end{array}$ & Case 1 & Case 2 \\
\hline Bleeding time & $4-7$ & $>12$ & $>15$ \\
$\begin{array}{l}\text { Platelet count in whole } \\
\text { blood }\left(\times 10^{9} / \mathrm{l}\right)\end{array}$ & $150-400$ & $12 \cdot 0-20 \cdot 0$ & $8 \cdot 0-34 \cdot 0$ \\
$\begin{array}{l}\text { Partial thromboplastin } \\
\text { time (sec) }\end{array}$ & $32-35$ & $28-32$ & 34 \\
Prothrombin time (\%) & $60-100$ & 100 & 100 \\
Thrombin time (sec) & $16-18$ & 22 & $17 \cdot 2$ \\
Anti thrombin III (\%) & $60-130$ & 128 & 82 \\
Plasma fibrinogen (mg/ml) & $150-400$ & 325 & 450 \\
Euglobulin lysis time (hr) & $>4$ & $2 \dagger$ & $>4$ \\
$\begin{array}{l}\text { Fibrin-fibrinogen degradation } \\
\text { products }(\mu \mathrm{g} / \mathrm{ml})\end{array}$ & $0-2$ & 2 & $<2$ \\
\hline
\end{tabular}

*The bleeding time was performed by modification of Ivy technique (Zahavi and Marder, 1974). Thrombin time was determined by the method of Hougie, 1972 and anti-thrombin III by the method of Biggs et al. (1970). Euglobulin lysis time was determined by the method of Nilson and Olow (1962), fibrinogen by thrombin turbidity (Ellis and Stransky, 1961), and fibrinogen degradation products by the method of Merskey (Merskey, Lalezari and Johnson, 1969).

†Decreased.

Bone marrow aspiration showed severe hypocellularity with complete absence of the megakaryocytes, presumably drug induced. Drug therapy with oxymetholone $300 \mathrm{mg}$ daily as well as prednisone $60 \mathrm{mg}$ daily was started and continued for 35 days with no changes in the platelet count which remained low $\left(6.0-30 \times 10^{9} / 1\right)$. The ECG, however, became normal and the patient was discharged. She was readmitted 10 days later because of fever $\left(39.5^{\circ} \mathrm{C}\right)$ and prostration. On admission, purpura was again generalized. Platelet count was still very low $(12 \cdot 0 \times$ $\left.10^{9} / 1\right)$. Septicaemia was suspected and gentamicin, carbenicillin and cephalosporin as well as infusions of platelet concentrates were administered i.v. without improvement. The patient became comatose and died 3 weeks later.

At post-mortem a massive haemorrhage in the posterior lobe of the right hemisphere of the brain was found. Most outstanding were the minimal arteriosclerotic changes in the coronary microcirculation. However, diffuse and confluent petechiae were apparent over the pericardium, endocardium and subendothelial tissue of the coronary arteries.

\section{Discussion}

At the time of initial evaluation and during the succeeding period, both patients exhibited severe thrombocytopenic purpura. The thrombocytopenia presumably prevented initial white thrombus formation which plays an important role in the initiation of thrombus (Mustard, 1974; Zahavi, 1975).

Both patients, however, developed subendocardial infarction, and on post-mortem examination of one of them, normal coronary arteries and diffuse pericardial and subendocardial petechiae were found. Since no obvious causes for these ischaemic changes such as increased work of the heart, severe anaemia or pulmonary embolism were found, it is possible that the damage was induced by the thrombocytopenia.

The impaired haemostasis in both patients was primarily due to pronounced thrombocytopenia, which was secondary to drug-induced marrow depression. The 2 patients received anti-inflammatory drugs before admission to hospital; these drugs may, in addition to the toxic effect on bone marrow, block the platelet release reaction and prolong the bleeding time (Zahavi, 1975). The last effect was not pertinent to the pathophysiology of the symptoms of these patients since it lasts for hours or days and disappears after drug withdrawal (Zahavi, 1975). Myocardial ischaemia in thrombocytopenia may be more frequent than hitherto appreciated and calls for careful electrocardiographic tracings in such patients.

\section{References}

BIGgs, R. et al. (1970) Antithrombin 3, antifactor Xa and heparin. British Journal of Haematology, 19, 283.

BowIE, E.S.W. \& OWEN, C.A. (1971) Clinical disorders related to blood platelet. In: The Circulating Platelet (Ed. Johnson, S.A.), p. 473. Academic Press Inc., New York.

CoHeN, P. (1974) Thrombocytopenia and myocardial ischemia. Journal of the American Medical Association, 228, 1568.

Ellis, B.C. \& Stransky, A. (1961) A quick and accurate method for the determination of fibrinogen in plasma. Journal of Laboratory and Clinical Medicine, 58, 477.

HougIE, C. (1972) Methods of estimating fibrinogen concentration. Hematology (Ed. Williams, W., Beatler, E., Ersler, A. \& Rundles, R. 1st edn, p. 1407. McGraw Book Co., London.

Merskey, C., Lalezari, P. \& Johnson, A.J. (1969) A rapid, simple, sensitivity method for measuring fibrinolytic split products in human serum. Proceedings of the Society for Experimental Biology and Medicine, 131, 871. 
MustaRD, J.F. (1974) Platelet and Thrombosis in Acute Myocardial Infarction. The Myocardium Failure and Infarction. (Ed. Braunwall, E.), p. 177. HP publishing Co. Inc. New York.

NiLson, I.M. \& Olow, B. (1962) Fibrinolysis induced by streptokinase in man. Acta chirurgica scandinavica, 123, 247.
ZAHAVI, J. (1975) Platelet function and endogenic metabolism, their relation to hemostasis and to clinical disorders of blood platelets. Harefuah, 89, 463.

ZAHAVI, J. \& MARDER, U.J. (1974) Acquired 'storage pool disease' of platelet association with circulating antiplatelet antibodies. American Journal of Medicine, 56, 883. 